fähigen Stoff wird ein Stück in Form eines Halbkreises geschnitten, mit einem zentralen, gleichfalls halbkreisförmigen Aussehnitt versehen und trichterartig zusammen gebogen. Die hierbei ühereinander gelegten Teile werden durch einige Drucklnnöpfe zusammen gehalten, deren Matrizen, beziehungsweise Patrizen, zu beiden Seiten des A ussehnitts längs des Halbkreisdurchmessers auf der Ober-, beziehungsweise Unterseite des Stoffes befestigt sind. Gleichzeitig wird hierdurch der Trichterkegel in sich abgedichtet. An einem dem Ausschnitt zunächst liegenden Druckknopfteil ist weiterhin ein starker Stoffstreifen drehbar angebracht; welcher bei dem ausgebreiteten Trichter paraliel mit der Wandung läuft, während er bei dem zusammengebogenen senkrecht abwärts gerichtet wird. In dieser Stellung regelt er den Ablauf des Filtrats, vertritt also das Trichterabflussrohr und verleiht zugleich dem Trichter selbst eine gewisse Festigkeit.

Fin neuer Gasentwicklungsapparat, von A. A. Besson ${ }^{1}$ ) herrührend, beruht in seiner Konstruktion auf altbekannten Prinzipien. Ein zylindrisches Gefäss trügt dicht über dem Boden einen Stutzen und ist an der Mündung mit einem Ebonitdeckel verschlossen. Durch eine passend eingeschnittene öffnung desselben wird eine Entwicklungshülse gesteckt in. Form eines weiten Reagensrohres, welches zur Aufnahme der festen Substanz des Gasentwicklungsmaterials dient und am unteren Teile mit einer Anzahl kleiner Öfnungen für den Eintritt der Säure versehen ist. Oben verschliesst die Hülse ein mit einem Gasableitungsrohr versebener, durchbohrter Stopfen. Die. Säure befindet sich in einem zweiten, gleichfalls mit einem Auslaufstutzen ansgerüsteten Zylinder. Die Stutzen beider Zylinder sind mit durchlochten Gummistopfen verschlossen, in welche Glasröhren eingesetzt werden, und mittels dieser durch einen Gummischlauch mit einander verbunden. Die Vorrichtung ist von der Firma Dr. Gö ckel in Berlin zu beziehen, während der Alleinvertrieb in der Schweiz der Firma Werthemann, Botty und Co. in Basel übertragen ist.

Eine verbesserte Gaswasch- und Absorptionsflasche, von C. $\mathrm{Hahn}^{2}$ ) angegeben, ist dem von $\mathrm{J}$. Walt e $\mathrm{r}^{3}$ ) konstruierten Gasabsorptionsgefäss, welches uur kleine Flüssigkeitsmengen aufzunehmen vermag, nachgebildet und hat die aus der Figur 9 auf Seite 266 hervorgehende Form erhalten.

1) Chemiker-Zeitung 38, 1041.

2) Zeitschrift f. angew, Chemie 26, I, 448.

s) Vergl. diese Zeitschrift 87, 586 (1898). 
Das in der Richtung des Pfeils durch das Einleitungsrohr strömende Gas gelangt in dessen als Injektorspitze i ausgezogenes Ende und wird

Fig. 9.

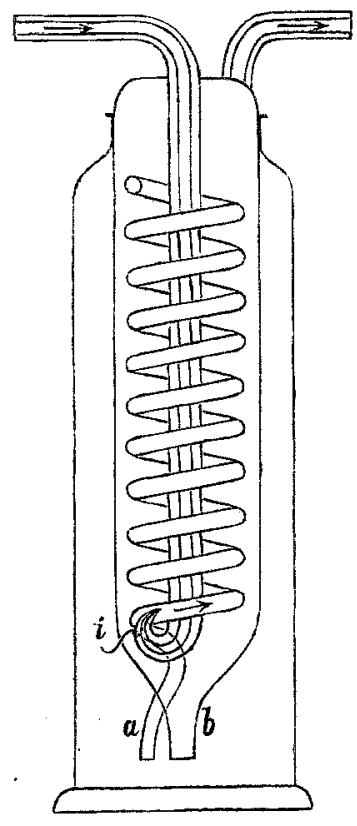
aus diesem in die $80-100 \mathrm{~cm}$ lange Glasschlange, in welche die Spitze eingeschmolzen ist, eingeblasen. Infolge der hierbei entstehenden Saugwirkung steigt durch das gleichfalls in die Schlange einmündende Röhrchen a frische Waschflüssigkeit aus dem Standgefäss in die Schlange hinanf, in welcher somit eine innige Berührung zwischen Gas und Lösung stattfindet. Die Waschflasche, welche sich besonders für die Untersuchung der Abgase in den Kaminen, der Endgase von Schwefelsäuresystemen, Salpeter- und Salzsäurekondensationen, Oleum- und Chlorkalkanlagen eignet, wird in verschiedenen Grössen durch die Vereinigten Fabriken für Laboratoriumsbedarf, Berlin N 39, hergestellt.

Als empfindlichen Indikator für Säuren und Basen empfiehlt Barth ${ }^{1}$ ) einen Farbstoff, den er aus der violetten

Kartoffel von Uruguay extrahiert bat.

Man kocht nach dem Verfasser die Knolle mit Wasser aus, hierdurch wird ein weinroter Farbstoff extrahiert. Den nun blau erscheinenden Rückstand mazeriert man mit starkem Alkohol. Die blaue Lösung wird durch Alkalien grün and durch Säuren wieder blan gefärbt.

II. Chemische Aualyse anorganischer Körper.

von

\section{H. Weber.}

Eine neue technische Methode zur Analyse von Handelszink hat E. J. Ericson ${ }^{y}$ ) vorgeschlagen. Nan lässt 19,2 $g$ der Probe mit

1) Rép. Pharm. IIT 26, 5; durch Pharm. Zentralhalle 55, 725.

2) The Journ. of Ind. and Engin. Chem. 5, 401 ; durch Chem. Zentralbi. 84, II, 84 . 